\title{
OSCAR FREIRE, COMO ENTOMOLOGISTA
}

\author{
(Discurso pronunciado pelo Prof. S. B. Pessôa \\ na Soc. de Med. Legal e Criminologia de São \\ Paulo em 15-XI-40)
}

Meus senhores!

Meu primeiro dever é vos dar, em nome de Frederico LANe e no meu próprio, nossos mais sinceros agradecimentos pela assinalada honra que nos confere a Sociedade de Medicina Legal e Criminologia de S. Paulo laureando nosso dèspreténcioso trabalho com o prêmio OSCAR Freire de 1940.

Ao Dr. Milton Amaral que se fez interprete da vośsa Companhia saudando-nos em vosso nome com palavras carinhosas e amigas - nossa gratidão.

Si é certo e verdadeiro tudo o que disse com referência a FREDERICO LANE, podeis desde logo avaliar, nas palavras com que a mim se refere, a velha amizade que nos une desde os bancos acadêmicos e o leva a esquecer meus muitos defeitos e exaltar miúdas qualidades, que só êle poude perceber.

$\mathrm{Na}$ sua personalidade vemos estampadas as virtudes que animam vossa Sociedade: servir a ciência pelo nobre interesse de servir o Brasil.

Tal foi tambem a vida do excelso patrono do prêmio que hoje acabais de nos outorgar: 'na sua existência, curta em anos, porém longa em trabalhos e vissicitudes, cultivou com amor e dedicação a ciência, realizando sua privilegiada inteligência as mais belas conquistas no domínio científico e seu nobre coração os mais profundos exemplos de amor à nossa terra.

Realizou seu alto ideal ao servir a ciência indígena cumprindo rigorosamente o compromisso assumido ao instalar a Cadeira de $\mathrm{Me}$ dicina Legal na nossa Faculdade:

"dando um ensino que não se limitou a reprodução servil da ciência estrangeira;

transmitindo aos seus discipulos o desejo veemente e o justo orgulho de obter seus conhecimentos na base firme da propria experiência;

batalhando para que tivessemos uma ciência verdadeiramente feita por nosso esforço, pelo nosso trabalho".

Eis o que realizou êste grande cientista e notável médico. 
Uma das facêtas mais interessantes da polimorfa inteligência de Oscar Freire foi seu pendor para os estudos de zoologia e, mais especialmente, para os de entomologia. Ao estudar a ecologia e sistemática dos insetos, procurava, sem duvida, aplicar tais pesquisas ao ramo dos conhecimentos ao qual dedicava suas mais constantes atividades - a Medicina Legal. Nem porisso deixou, entretanto, de legar à entomologia pura as mais diversas e interessantes contribuições para a sistemática, biologia, ecologia e distribuição geográfica das espécies.

Graças ao seu nobre discípulo e meu prezado amigo Prof. Flamínto FÁvero, continuador, na nossa Faculdade, da escola científica de OsCAR FrEIRE, conseguí ler as numerosas contribuições legadas por êle à ciência, nêste particular. Dignas de análise por um melhor especialista do que aquele que hoje vos fala, deixam elas entretanto entrever, mesmo aos mais desajuizados, o carinho com que OsCAR FrEIRE procedia as suas observações, e a minúcia com que variava as condições experimentais afim de verificar com exatidão as hipóteses formuladas por seu espírito. Nunca se deixou vencer pelos obstáculos ou pelas dificuldades; tinha fé na ciência, poder na tenacidade e força na paciência; nunca se desencorajava na solução de um problema, pois sabia que nada pode contra a vontade. Pois não foi êle, ainda moço, quem disse em um de seus primeiros discursos "Ao trabalho", deve ser o lema de todo homem?

Sua contribuição à entomologia acha-șe dispersa em várias revistas e folhetos; penso seria bastante útil e vantajoso o reunirem-se estas suas numerosas contribuições sôbre os artrópodos cadavéricos em um único volume, de grande proveito não só para os médicos legistas como também para os entomologistas brasileiros.

Não se fiava somente na observação, porém escrupulaso investigador, verificava com experiências várias e repetidas aquilo que the apresentava a natureza. Assim ao refutar a teoria admitida pela maioria dos autores clássicos da época, de que as larvas da Musca domestica são necrófagas, diz OSCAR FREIRE que suas observações de quasi oito anos depõem contra a frequência, porém pela raridade da postura da Musca domestica nos cadáveres humanos ou de animais outros em putrefação. "A-pesar de ser ela uma das moscas mais assíduas nos cadáveres, nunca conseguiu surpreender-lhes a postura no corpo em decomposição pútrida, o que entretanto conseguiu com a maioria, quasi totalidade das moscas de igual frequência". Esta observação, a-pesar de ser de quasi oito anos, ainda não o satisfaz. Agora experimenta, expondo em locais em que era abundante a $M u s-$ ca domestica, cadáveres de diversos animais (cobaias, cães, gatos, etc.) em decomposição, nunca obtendo larvas de Musca domestica. Si, porém, depositava, no mesmo local estrume de cavalo ou de boi, .o resultado positivo não se fazia esperar: " 24 horas depois pululavam de larvas". 
Em outra interessante nota, estudando a fauna 'cadavérica da. Baía, descreve de maneira minuciosa a biologia tão interessante da Synthesiomyia brasiliana, mosca que nos parece rara em S. Paulo, porém abundante e constante nos cadáveres naquele Estado, conforme suas observações.

"Observei, diz Óscar Frelre, um curioso hábito na formação đo pupário. As larvas revestem-se de uma substância gelatinosa, que secretam em abundância e envolvem-se nos pêlos, cabelos, terra, areia, serragem, nos detritos enfim que encontram próximo do cadaver e aí se transformam em pupas, havendo em cada grupo muitas dezenas de pupas".

Estudou Oscar FreIre pormenorisadamente a Cochliomyia macellaria, por ser, como diz, dos dípteros necrófilos o mais abundante.

E' interessante o fato de ter êle assinalado já em 1914 úma espécie de Cochliomyia diferente da $C$. macellaria; não havendo terminado o estudo desta espécie, da qual porém possuia larva, pupa e imago, denomina-a provisoriamente de Compsomyia (FCochliomyia) Lutzi n. sp.. Diz êste autor textualmente: "ao lado da $C$. macellaria Fabr., que produz entre nós a miíase cavitária, existe uma outra espécie, até agora só encontrada em cadáveres - a Cochliomyia Lutzi n. sp.".

Assim FrEIRE já houvera notado em 1914, o que 20 anos depois constiţuiu importante descoberta de Cushing e Patron; sôbre a existência real de duas espécies confundidas sob um único nome: $C$. macellaria que nos parece ser idêntica a lutzi de OSCAR FREIRE, só atacando cadáveres e a Cochliomyia hominivorax, de Coquerel 1858, considerada durạte muitos anos sinónima de macellaria, e que produz as miíases do homem e dos animais e que tão grandes prejuizos traz à economia humana.

Não me posso furtar de referir, ainda que de passagem a um outro interessantíssimo trabalho do ilustre professor baiano, sôbre formigas necrófagas brasileiras, onde além de estudar os hábitos de várias espécies, assinala, pela primeira vez a necrofilia da Componutus abdominalis v. atriceps. Estuda também, com abundância de detalhes a Solenopsis geminata (Fabr.), denominada pelo povo de formiga de fogo ou lavapés. Curiosa é a crença dos habitantes de Aveiro (Estado do Pará), relativa à origem dessa praga, e que foi recolhida pelo naturalista BATEs: "Acreditava aquela gente simploria que a formiga de fogo, desconhecida no Tapajoz antes da Cabanada, revolta em 1832 iniciada em Pernambuco e depois espalhada pelo Norte surgiu do sangue dos rebeldes trucidados". RoQUETTE Pinto crê que se pode dar àquela crendice popular uma origem direta. "Porque todos os sertanejos sabem que a formiga de fogo aparece como por encanto no corpo de qualquer animal que se deixar morto no campo. Mata-se uma cobra, p. exp., e algumas horas depois lá está o enxame de himenópteros limpando os ossos do ofídio 
com uma rapidez que faz inveja aos preparadores de zoologia, os quais não se envergonham, aliás, de pedir muitas vezes às formigas a prestação dêste serviço... Não admira, pois, que sôbre os corpos dos cabanos as solenopsis houvessem aparecido em legiões, favorecendo dest'arte, o surto da lenda referida".

No trabalho citado publica Oscar FreIre um pequeno catálogo das principais espécies de formigas brasileiras necrófilas.

"Consoante o calculo de Groeldi o Brasil concorre aproximadamente com a quarta parte das quasi 500.000 espécies de formigas existentes no globo. Tal seu número, hoje, como dantes que delata o testemunho de MARCGRAF, os portuguêses já a intitulavam, nos tempos da colonia, de "Rainhas do Brasil". (Formicae hic sunt tanto numero ut a Lusitanis "Rey do Brasil" appelantur). Termina Oscar Freire com um voto, ainda hoje, ao que saibamos não cumprido - "Possa esta nota despertar nos competentes o desejo de organização de prestimoso catálogo das formigas necrófagas brasileiras".

Como todo bom entomologista que se preza, não deixou Oscar FreIRe de se aventurar nas quizílias de nomenclatura; e publica na Gazeta Medica da Baía, um bem lançado artigo sôbre uma questão de nomenclatura, em que discute a prioridade do nome Compsomyia sôbre Chrysomyia para a mosca Macellaria; hoje não subsiste nem um nem outro mas sim o de Cochliomyia. As citações que faz no original da velha literatura entomológica, de difícil consulta mesmo nas melhores bibliotécas especializadas de nosso país, mostram quão rica era a sua bibliografia zoológica. Não deixa também de defender a.importância da sistemática, o que muito deve encantar ainda hoje os nossos̀ sistematistas, que dificilmente deixam certos animais permanecerem com o mesmo nome, por mais de alguns poucos meses... "Não se tenha esta questão de nomes por desprezível bizantismo científico, diz o mestre. Sem uma nomenclatura bem assentada e escrupúlosamente cumprida e respeitada, nã்o haverá meio de entenderem-se os entomologistas".

Deixou ainda FREIRE numerosas observações sôbre grande número de espécies que seria longo aqui assinalar.

Um apanhado geral de toda fauna cadavérica brasileira é desenvolvido na sua monumental conferência, realizada em 1921 no Centro Acadêmico Oswaldo Cruz. Nela não se sabe o que mais admirar - a perícia do escritor ou a competência do entomologista.

Não me furto ao prazer de dar um exemplo de um e de outro - Ao falar das abelhas: "Conheceis bem as abelhas que só nos trazem a idéia das flores que constituem o seu alimento predileto. Já um poeta querendo exalçar o perfume de uma boca gentil, rubra, como uma corola, contou que, por engano as abelhas nela vinham pousar desejosas e inquietas. Com que cara ficaria o poeta, e em que furor não ficaria a amada, si soubessem que as abelhas também vão aos cadaveres, que não é raro encontrarem-se em certo número. 
nas fases em que é mais intenso o odor putrefativo, em que é mais forte o delíquio pútrido".

Nêste outro trecho, pensamos ser um FABRE que escreve, tal a. perfeição e a vida com que é relatada a observação:" "Também é preciso distinguị na população da fauna cadavérica um outro grupo que tem iludido muito observador, a classe dos, perdoae a expressão antropomorfa, insetos bandidos, insetos ladrões, os predatórios. Vão ter ao corpo, não para entrar no festim neçrófago, nem levados de interesse pela prole que aí deverá viver, mas em busca de caça para apanhar outros insetos, larvas ou adultos, são caçadores que fazem do cadaver a'sua séva habitual. $E^{\prime}$ por vezes um gosto ver as manhas e astúcias com que, vigilantes e empreendedores surpreendem e atacam as larvas inertes e indefezas ou os adultos ageis e avisados".

- Meus senhores - estou certo não ser necessário pedir-vos me perdoeis a extensão destas páginas; bem sei da benevolência do vosso juizo - sendo sempre para nós um prazer repassar êstes admiráyeis trechos da obra de entomologia forense de Oscar FreIre. Foi porisso que abusei de vossa condescendência por me saber "a priori" desculpado.

Pensei nada melhor vos poderia dizer no momento que vos agradeço a láurea que nos dais do nome tutelar de OsCAR FreIRE, do que vos recordar uma pequena parte de sua vasta produção intélectual.

Merecem a forma perene do livro estas joias finissimas de seu talento, dispersas em artigos, revistas e discursos que nos fazem sempre amar seu espirito e reverenciar sua memória. 